\title{
Arbor
}

\section{La Salud: un bien básico}

\author{
Javier Claros González
}

Arbor CLXXX, 710 (Febrero 2005), 321-326 pp.

\section{De dónde venimos}

Con las últimas transferencias, a principios del año 2002, se cerró un proceso que se había iniciado años atrás en las Comunidades Autónomas llamadas históricas. Con ellas se repitió el tan manido dicho de «los árboles no dejan ver el bosquen, siendo los árboles en este caso la Atención Especializada (AE) y el bosque la Atención Primaria (AP). Una ver más, el sustrato del que se alimenta la AE, es decir, la AP (puerta de entrada al Sistema Nacional de Salud, elemento distribuidor y dinamizador del mismo), es considerada a la hora de las transferencias económicas como la Cenicienta del sistema.

Con todo ello, lo que se pone en peligro es la reforma de 1984 (R.D. 137/84 Estructuras Básicas de Salud) por la que se crearon las Áreas de Salud, las Zonas Básicas de Salud y se apostó por la AP, así como el desarrollo de la especialidad en Medicina Familiar y Comunitaria nacida al albor de la Declaración de Alma-Ata (allá por 1978), en la que se definía la AP cómo el «eje del sistema sanitario».

\section{Dónde estamos}

Tres años después de haberse finalizado las transferencias sanitarias, nos encontramos con la reforma de 1984 sin concluir; es cierto que tenemos un Servicio Nacional de Salud eficaz con un nivel de gastos bajo (por debajo de la media europea) y con una atención de calidad (según la OMS, entre los 10 primeros del mundo) pero con graves problemas de financiación en AP, con disminución del porcentaje del PIB en los 10 últimos años y aumento en las prestaciones y en la población protegida, lo 
que se traduce en masificación, listas de espera e incremento del gasto farmacéutico; mientras que en $\mathrm{AE}$ y gasto de farmacia nos acercamos en los últimos 10 años a niveles europeos. Este retraso respecto a los países europeos, a la vez que el gasto farmacéutico crece sin control, es indicativo de lo que pasa en un país no rico que gasta poco en Sanidad. Lo que se propone es no sólo detener el gasto farmacéutico, sino invertirlo como más adelante analizaré. Éste debe ser el primer reto de la Sanidad Pública en las CC.AA.

Estamos, por tanto, al borde de la cuarta operación de saneamiento desde 1985. No sólo debemos estudiar la financiación per cápita (teniendo en cuenta el envejecimiento de la población y la dispersión de la misma), sino también dar solución a las desigualdades entre las CC.AA., pactando una cartera mínima de servicios común a todas las CC.AA. y una financiación que la haga posible. Cualquier nuevo servicio que se incorpore a la cartera deberá ir acompañado de la financiación correspondiente sin descartar el «copago», palabra maldita pero real que debe llevar a la unión de los distintos partidos políticos en pos de un compromiso con la viabilidad del Sistema Sanitario y más aún cuando ya es latente la necesidad de establecer prestaciones socio-sanitarias, dado el envejecimiento y dependencia de una parte importante de los ciudadanos.

\section{Hacia dónde vamos}

\subsection{Deficiencias y soluciones}

En AP, debido a las características de la organización de los equipos (ya que es la puerta de entrada del usuario al Sistema Sanitario), una fortaleza no trabajada se convierte en una debilidad, así como una debilidad estudiada puede llevarnos, con más o menos esfuerzo y aprovechando las oportunidades, a una fortaleza; esto lo explica la accesibilidad del usuario al Sistema Sanitario en AP, accesibilidad que siendo en si una fortaleza, se transforma en una debilidad si no sustituimos en la medida de lo posible las visitas a demanda (frecuentación) por las visitas concertadas-programadas. En la actualidad, paradójicamente, no sólo no las controlamos sino que las aumentamos con visitas de complacencia o innecesarias por el afán de controlar factores de riesgo que el usuario no se compromete a corregir; si sus estilos de vida no son adecuados poco podremos hacer por su salud por más que lo hagamos acudir a nuestras consultas médicas y de enfermería. 


\subsection{Entre las deficiencias encontramos}

A Estructura

A.1. Física:

- Ineficaz distribución de los recursos humanos, con cupos desajustados, primando la accesibilidad (consultorios periféricos con un equipo médico-DUE) sobre la eficiencia. En zonas urbanas cupos no zonificados ni uniformes.

- Desmotivación de los profesionales tras años comprometidos con el Sistema de Salud.

\section{A.2. Material}

- Tras un esfuerzo inicial en construcción de Centros de Salud, se aprecia una falta de previsión tanto en renovación de instrumental tecnológico como de inversión en mantenimiento y mejoras en los centros.

- Falta de inversiones en nuevas tecnologías.

\section{B. Organización}

- Agenda rígida en consultas.

- Masificación de las consultas.

- Poco tiempo dedicado a consulta concertada-programada por no poder controlar la demanda.

- Listas de espera en fechas clave.

- Enfoque puramente asistencial-curativo.

- Poco desarrollo de las actividades de promoción de la salud, prevención de la enfermedad y educación para la salud, siendo estas actividades mayoritariamente voluntarias.

- Poca previsión, con una población cada vez más envejecida y portadora de enfermedades crónicas.

- Demanda cada vez mayor de prestaciones más sociales que sanitarias.

- Limitación de acceso a nuevos recursos tecnológicos.

C. Financiación capitativa cuando debería ser en función de la cartera de servicios, envejecimiento de la población y dispersión de la misma.

D. Gasto farmacéutico en crecimiento exponencial año tras año. 
E. Cartera de servicio desigual entre las CC.AA.

F. Participación ciudadana escasa o nula, con lo que es difícil que el usuario se comprometa con el Sistema de Salud y lo vea más como un bien de consumo que como un bien básico.

G. Deficiente coordinación entre AP y AE.

\subsection{Como soluciones proponemos}

- Consolidar los puestos de trabajo agilizando los traslados y las oposiciones (como máximo deben ser cada dos años).

- Definir lo que es puesto de trabajo rural y urbano, así como sus características específicas, retribuciones y puntuación para la promoción de los trabajadores.

- Delimitar el tamaño de los equipos (no debe superar las 20-25 personas), así como definir las Unidades Básicas Asistenciales (dos médicos, un DUE, y un auxiliar administrativo como un modelo a discutir).

- Edificios físicos atractivos, funcionales y con planes de renovación y mantenimiento.

- Agendas gestionadas y abiertas que primen lo concertado sobre la demanda.

- Informatización con historia clínica unificada AP-AE, receta electrónica, gestión desde AP de las derivaciones a AE.

- Catálogo de pruebas diagnósticas, perfiles definidos, resultados de la analítica en línea en el día.

- Guías clínicas y de prescripción elaboradas por las sociedades científicas y consensuadas para darles credibilidad y compromiso de cumplimiento.

- Definir funciones de Enfermería, con más peso de las actividades de Promoción, Prevención y Educación para la Salud.

- Capacidad de respuesta a la demanda en horario del centro, evitando la derivación al Servicio de Urgencias.

- Financiación que tenga en cuenta el envejecimiento de la población y la dispersión de la misma. Los nuevos servicios que asuma la AP deben venir con su financiación correspondiente invirtiendo el actual hospitalocentrismo (mientras que en Europa 2 de cada 4 profesionales trabajan en AP, en España 3 de cada 4 trabajadores lo hacen en $\mathrm{AE}$ ). 
- Incentivación-productividad de los trabajadores no exclusivamente económica.

- Desarrollo de la carrera profesional.

- Política de recursos humanos.

- Gasto farmacéutico donde prime la relación prescripción/precio con incremento en la prescripción de fármacos genéricos, se tienda a disminuir el consumo de fármacos y a comprometer al usuario por mejorar sus estilos de vida, así como no financiar los fármacos que no aportan nada o de baja utilidad terapéutica.

- Cartera de servicios mínima unificada para todas las CC.AA.

- Programas de docencia e investigación.

- Formación continuada obligatoria.

- Mejor entendimiento y comunicación entre los gestores y los clínicos.

- Desarrollar la participación ciudadana, único vínculo que llevará al usuario a considerar el sector salud como un bien básico y no un bien de consumo (cada vez es más frecuente, ante el incremento de la frecuentación, la anécdota del médico que, echando en falta al paciente que acudía todas las semanas a su consulta, al fallar una visita y preguntarle en la siguiente qué le había pasado la semana anterior, obtiene por respuesta "es que estuve enfermo»).

- Coordinar la AP con la AE, no con la tentación de implantar las gerencias únicas, sino con la creación de comisiones de trabajo a nivel de direcciones (médicas, de enfermería, unidades de apoyo, unidades administrativas, etc.) que sean operativas y resolutivas.

Como conclusión, podemos definir los siguientes retos para la AP en un futuro a corto plazo:

1 Mayor financiación.

2 Mejor planificación de los recursos.

3 Nueva organización de los servicios.

4 Pacto entre gestores y clínicos.

5 Informatización y sistemas de información.

6 Desarrollo de la carrera profesional.

7 Coordinación entre AP y AE.

Y como epílogo dejamos para la reflexión:

- «La AP no debe ser considerada como un filtro, sino como la puerta de entrada de los usuarios al Servicio de Salud, dentro del cual debe seguir a los mismos». 


\section{Javier Claros González}

326

- «El éxito de la organización es saber adaptarse continuamente al cambio».

- «Hacer caso a las encuestas de satisfacción y no olvidar que la evaluación en Salud no puede paralizar la acción».

- «El envejecimiento lleva a una mayor comorbilidad y yatrogenia».

- «Internet está cambiando el modelo de relación médico-paciente».

- «[El informe Fernando Abril Martorell de 1991] sigue vigente en muchos de sus puntos».

- «La gestión es la puesta en ejecución de unos métodos logísticos más o menos validados, sobre los que el sentido común actúa como un gran catalizador». 